\title{
Germinação de sementes de Physalis angulata L.: estádio de maturação do cálice e forma de armazenamento ${ }^{1}$
}

\author{
Tereza Cristina de Carvalho², Jessica Welinski de Oliveira D'Angelo², \\ Gustavo Nunes Scariot ${ }^{2}$, Luiz Alberto Saes Júnior ${ }^{2}$, Francine Lorena Cuquel ${ }^{2}$
}

\begin{abstract}
Germination of Physalis angulata L. seeds: calyx maturation stage and form of storage

The harvest stage of Physalis angulata L. aiming human consumption is set in literature. However, there are no criteria for harvesting fruits for seed propagation. This study aimed to determine the harvest stage of $P$. angulata $\mathrm{L}$. seeds according to the fruit calyx color, as well as evaluating their storage viability. For that, fruits were harvested from matrix plants, considering three maturity stages, according to the calyx color (green, yellow and yellow-brownish). A completely randomized design was used, in a factorial arrangement comprising two kinds of package (paper bag and glass container) and four evaluation periods (after harvesting and at 45, 90 and 135 days after storage - DAS), being isolated the factor storage environment. It was concluded that $P$. angulata seeds should be collected from fruits with a green calyx and used soon after being harvested, since seed germination sharply decreases after 45 DAS, both in the storage chamber and in the refrigerated environment, regardless of whether glass or paper is used.
\end{abstract}

KEY-WORDS: Physalis; harvest stage; physiologic quality.

\section{INTRODUÇÃO}

A Physalis sp. é comumente conhecida como camapu, fisalis, juá-de-capote ou mullaca. Pertencente à família das solanáceas, a maior parte da diversidade de plantas desse gênero é encontrada na América do Sul (Hunziker 2001, Souza \& Lorenzi 2005), sendo que, no Brasil, já foram catalogadas 11 espécies (D'arcy et al. 2005), distribuídas por todo o território nacional. É uma planta herbácea, ereta, medindo 40-70 cm de altura (Lorenzi \& Matos 2008), podendo alcançar dois metros, se conduzida por tutoramento, sendo uma planta anual e que se reproduz por semente (Souza et al. 2010).

\section{RESUMO}

O ponto de colheita de Physalis angulata L., visando à obtenção de frutos para consumo humano, é indicado na literatura. Entretanto, não são estabelecidos critérios de colheita de frutos para a aquisição de sementes. O trabalho objetivou determinar o ponto de colheita de sementes de P. angulata L., de acordo com a coloração do cálice dos frutos, bem como avaliar a viabilidade do seu armazenamento. Para isso, foram colhidos frutos de plantas matrizes, em três estádios de maturação, levando-se em consideração a coloração do cálice (verde, amarelo e amarelo-amarronzado). Utilizou-se delineamento inteiramente casualizado, em esquema fatorial compreendendo dois tipos de embalagem (saco de papel e recipiente de vidro) e quatro épocas de avaliação (logo após a colheita e aos 45, 90 e 135 dias após o armazenamento - DAA), sendo isolado o fator ambiente de armazenamento. Concluiu-se que sementes de $P$. angulata devem ser obtidas de frutos com cálice de coloração verde e utilizadas logo após a colheita, uma vez que há perda expressiva na germinação das mesmas, após 45 DAA, tanto em câmara de armazenamento quanto em ambiente refrigerado, independentemente se utilizada embalagem de vidro ou de papel.

PALAVRAS-CHAVE: Fisalis; ponto de colheita; qualidade fisiológica.

Estudos sobre sementes de Physalis sp. abordam vários aspectos, como propriedades farmacológicas com ação antimicrobiana e anticâncer (Lopes et al. 2006, Soares et al. 2006), morfologia de sementes, testes de vigor e osmocondicionamento (Souza et al. 2010, Souza et al. 2011, Oro et al. 2012). No entanto, verifica-se que são escassas pesquisas que indicam o melhor ponto de colheita dos frutos, para a obtenção de sementes, visando a constituir novas semeaduras.

Rufato et al. (2008) recomendam a colheita de Physalis sp. para o consumo humano quando o cálice apresenta coloração amarela, por se constituir uma opção para obtenção de frutos de melhor qualidade. Tal fato é importante, pois a sua colheita no momento

1. Trabalho recebido em set./2013 e aceito para publicação em set./2014 (n registro: PAT 26628).

2. Universidade Federal do Paraná (UFPR), Departamento de Fitotecnia e Fitossanitarismo, Curitiba, PR, Brasil. E-mails: tcdcarva@gmail.com, jessica_welinski@hotmail.com, gustavoscariot@hotmail.com, lsaesjr@gmail.com, francine@ufpr.br. 
adequado pode prolongar a vida de prateleira do fruto (Ávila et al. 2006, Rodrigues et al. 2012).

Nesse sentido, Fischer \& Martinez (1999) classificaram os frutos de Physalis sp. para o consumo humano, depois de colhidos, conforme a coloração da epiderme, em seis classes: verde, amarelo-alaranjado, laranja-claro, laranja, laranja-escuro e laranja avermelhado, sendo as três últimas classes as que apresentaram as melhores características físico-químicas para o consumo humano. Entretanto, conforme ressaltou Andrade (2008), a coloração da epiderme do fruto não é a referência do ponto de colheita, uma vez que o cálice está totalmente fechado, impedindo a visualização da coloração do fruto. Outros estudos constatam que o ponto de colheita dos frutos para consumo humano depende da coloração do cálice (Chitarra \& Chitarra 2005, Ávila et al. 2006, Rufato et al. 2008, Lima et al. 2009, Rodrigues et al. 2012).

Como o momento adequado para a colheita dos frutos nem sempre coincide com o ponto de maturidade fisiológica das sementes, esse estágio pode ocorrer em frutos ainda em fase de maturação (Dias 2001). Desse modo, torna-se relevante um estudo da associação do ponto de colheita de Physalis angulata com a obtenção de sementes, para constituir novas semeaduras.

$\mathrm{Na}$ literatura, existem poucas informações sobre a melhor forma de conservar a viabilidade das sementes de Physalis sp. (Souza et al. 2014). Apesar de possuir sementes ortodoxas, ou seja, tolerantes à secagem até níveis de baixos teores de água, o favorecimento do armazenamento por longos períodos pode depender de outros fatores, como o momento adequado da colheita e o processamento das sementes (Souza et al. 2014).

Nesse sentido, este trabalho objetivou determinar o ponto de colheita de sementes de Physalis angulata L., de acordo com a coloração do cálice dos frutos, e avaliar a viabilidade do armazenamento das sementes.

\section{MATERIAL E MÉTODOS}

O trabalho foi conduzido no Laboratório de Análise de Sementes do Departamento de Fitotecnia e Fitossanitarismo da Universidade Federal do Paraná, em Curitiba (PR), de março a outubro de 2012.

As sementes de Physalis angulata L. foram obtidas de plantas matrizes cultivadas na Estação Experimental do Canguiri da Universidade Federal do Paraná, em Quatro Barras (PR), sendo os frutos colhidos em março de 2012. A colheita dos frutos foi realizada com base na escolha aleatória de 50 plantas, sendo os frutos selecionados de acordo com a coloração do cálice, segundo a seguinte classificação: a) coloração verde; b) coloração amarela; c) coloração amarelo-amarronzada.

Após a colheita, os frutos foram novamente selecionados, eliminando-se aqueles que apresentavam danos, sendo que os íntegros foram despolpados em água deionizada. As sementes removidas da polpa e acondicionadas sobre papel filtro seco foram mantidas em ambiente de laboratório, sob temperatura de $20 \pm 1^{\circ} \mathrm{C}$, durante cinco dias, para eliminar o excesso de água.

A avaliação da qualidade inicial dos lotes (Tabela 1) foi realizada por meio da determinação do teor de água e do teste de germinação (Brasil 2009).

As avaliações realizadas nas sementes, após a colheita e depois de 45, 90 e 135 dias de armazenamento, foram as seguintes: a) determinação do teor de água: método de estufa a $103 \pm 2^{\circ} \mathrm{C}$, por 24 horas (Brasil 2009), utilizando-se duas repetições de aproximadamente $0,5 \mathrm{~g}$ de sementes. Os resultados foram expressos em percentagem média, em base úmida; b) teste de germinação: foram utilizadas quatro subamostras de 50 sementes (totalizando 200 sementes para cada tratamento), distribuídas sobre areia de granulometria fina previamente esterilizada e umedecida com quantidade de água equivalente a $60 \%$ da capacidade de campo e mantidas em caixas de plástico $(11 \mathrm{~cm} \times 11 \mathrm{~cm} \times 3 \mathrm{~cm})$, no interior de estufa incubadora do tipo B.O.D., em fotoperíodo de oito horas de luz a $30^{\circ} \mathrm{C}$ e 16 horas no escuro a $20^{\circ} \mathrm{C}$ (Brasil 2009). Os resultados foram expressos em percentagem média de plântulas normais para cada tratamento.

Paralelamente, as sementes foram armazenadas, visando a obter informações quanto às condições

Tabela 1. Teor de água e germinação de sementes de Physalis angulata L. coletadas de frutos em distintos estágios de maturação (Curitiba, PR, 2012).

\begin{tabular}{|c|c|c|}
\hline \multirow{2}{*}{ Estágio de maturação } & Teor de água & Germinação \\
\hline & \multicolumn{2}{|c|}{$\%$} \\
\hline Cálice verde & 9,6 & 89,0 \\
\hline Cálice amarelo & 7,9 & 23,0 \\
\hline Cálice amarelo-amarronzado & 7,9 & 40,0 \\
\hline $\mathrm{CV}(\%)$ & - & 10,6 \\
\hline
\end{tabular}


mais adequadas para a conservação da viabilidade do material. Para o estudo, as sementes foram acondicionadas em dois tipos de embalagem: saco de papel do tipo $\mathrm{Kraft}^{\circledR}$ (embalagem porosa) e recipiente de vidro (embalagem hermética). Foram testadas duas condições de ambiente: câmara de armazenamento com controle de temperatura e umidade relativa do ar $\left(14^{\circ} \mathrm{C}\right.$ e $60 \%$ de umidade relativa do ar) e refrigerado $\left(7 \pm 2^{\circ} \mathrm{C}\right.$ e $45 \%$ de umidade relativa do ar). As avaliações foram realizadas em quatro períodos: logo após a colheita, aos 45, 90 e 135 dias após o armazenamento.

Os dados obtidos em cada teste, exceto para a determinação do teor de água, foram analisados de acordo com delineamento inteiramente casualizado, com quatro repetições, em esquema fatorial $2 \times 4$, compreendendo dois tipos de embalagem (hermética e porosa) e quatro épocas de avaliação (após a colheita e aos 45, 90 e 135 dias de armazenamento), sendo isolado o fator ambiente de armazenamento para cada análise fatorial. Os dados obtidos foram submetidos à análise de variância e as médias comparadas pelo teste de Scott-Knott $(\mathrm{p} \leq 0,01)$. Utilizou-se o programa estatístico Assistat (Silva 2008).

\section{RESULTADOS E DISCUSSÃO}

Pelos dados do teor de água inicial das sementes (Tabela 1), verificou-se que aquelas obtidas de frutos com coloração do cálice verde apresentaram o maior teor de água $(9,6 \%)$, em comparação às sementes coletadas de frutos com cálice amarelo e amarelo-amarronzado (7,9\%).

Sementes provenientes de frutos carnosos, normalmente, passam lentamente pela fase de desidratação, atingindo teores de água em torno de $40,0 \%$, após a maturidade fisiológica (Carvalho \& Nakagawa 2000, Dias 2001). Para P. angulata (Tabela 1), sementes originadas de frutos com coloração do cálice verde apresentaram o maior teor de água, quando comparadas com as provenientes de frutos com cálice amarelo e amarelo-amarronzado. Vale ressaltar que as sementes provenientes de ambos os frutos passaram pelo mesmo processo de desidratação, depois de extraídas. Essa resposta indica que sementes contidas nos frutos com cálice verde, logo depois de colhidas, apresentam maior teor de água dentro dos frutos, em relação aos demais pontos de maturação (cálice amarelo e amarelo-amarronzado). Consequentemente, o maior período de permanência dos frutos em campo acarreta em dessecação natural das sementes.

No caso de $P$. angulata, assim como ocorre para hortaliças de frutos carnosos, a maturidade fisiológica das sementes comumente ocorre com o início da mudança de coloração dos frutos, ou seja, frutos verdes apresentam alterações na coloração, passando a adquirir tons avermelhados (Chitarra \& Chitarra 2005). Como ressaltado por Dias (2001), nem sempre há necessidade de esperar pela maturação completa dos frutos para retirar as sementes, pois a maturidade fisiológica das sementes pode ocorrer em frutos ainda em fase de maturação, ou seja, com coloração verde.

A germinação das sementes de $P$. angulata obtidas de frutos colhidos com distintas colorações de cálice encontra-se na Tabela 1. Pelos dados do teste de germinação, foi possível classificar as sementes colhidas com cálice verde como de alta viabilidade ( $89 \%$ de germinação) e as colhidas com cálice amarelo-amarronzado como de viabilidade intermediária (40\% de germinação), ficando as sementes colhidas de frutos com cálice amarelo em posição inferior (23\% de germinação).

Pelas normas para produção, comercialização e utilização de sementes (Brasil 2013), existem índices de germinação estabelecidos para cada espécie que devem ser respeitados, para haver comercialização de lotes de sementes. Embora ainda não se tenha um padrão para comercialização de sementes de $P$. angulata L., os valores obtidos de germinação para sementes contidas em frutos com cálice amarelo e amarelo-amarronzado (Tabela 1) são muito baixos para indicá-los como pontos de maturidade para a colheita de frutos, visando à obtenção de sementes para novas semeaduras.

Assim, verificou-se que sementes advindas de frutos com coloração do cálice verde apresentaram a máxima germinação (Tabela 1). Esse fato coincidiu com o máximo teor de água das sementes $(9,6 \%)$, ao compará-las com as sementes advindas de frutos de cálice amarelo e amarelo-amarronzado (ambos com $7,9 \%$ de água). Esse resultado pode estar associado ao maior período de permanência dos frutos em campo, ocasionando diminuição na viabilidade das sementes, uma vez que as mesmas já atingiram o ponto máximo de acúmulo de matéria seca e estavam na fase de desidratação natural.

Conforme destacado por Dias (2001), o desenvolvimento das sementes pode ser acompanhado por vários fatores, segundo características físicas e 
fisiológicas, como o teor de água e a germinação. Desse modo, constatou-se que a associação do teor de água das sementes de $P$. angulata $(9,6 \%$ de água) com a obtenção da melhor germinação (89\%) favoreceu a colheita dos frutos com coloração do cálice verde.

Levando-se em consideração que o ponto de maturação com cálice de coloração verde resultou na melhor resposta para obtenção de sementes com a máxima germinação (Tabela 1), dados apresentados para o armazenamento das sementes (Tabela 2), germinação em distintos ambientes e diferentes embalagens (Tabela 3 ) foram gerados para sementes obtidas apenas de frutos com cálice de coloração verde.

Ao analisar os resultados apresentados na Tabela 2, verificou-se que os dados do teor de água para as sementes obtidas de frutos com cálice de coloração verde apresentaram resultados distintos, conforme o ambiente e a embalagem adotados. Assim, as sementes armazenadas em embalagem hermética (vidro) foram aquelas que obtiveram os menores teores de água, em relação àquelas armazenadas em embalagem porosa (papel). Isso se dá em função de a embalagem hermética não permitir trocas de vapor de água da semente com o ambiente externo, diferentemente do que ocorre com as sementes armazenadas em embalagens porosas (papel), uma vez que são higroscópicas.

Vale ressaltar que o teor de água das sementes embaladas em recipientes à prova de umidade deve ser reduzido para $4,0-8,0 \%$, pois, do contrário, a deterioração das sementes será mais acelerada, em relação às sementes condicionadas em embalagens porosas sob condições ambientais (Carvalho \& Nakagawa 2000, Nascimento 2009).

Quanto ao teor de água das sementes nos distintos ambientes de armazenamento (Tabela 2), observou-se que as sementes armazenadas em ambiente controlado $\left(14^{\circ} \mathrm{C}\right.$ e $60 \%$ de umidade relativa do ar) apresentaram os maiores valores de teor de água, independentemente da embalagem utilizada. Quanto ao armazenamento em refrigerador $\left(7 \pm 2^{\circ} \mathrm{C}\right.$ e $45 \%$ de umidade relativa do ar), com a menor temperatura, essa condição pode ter permitido que as sementes atingissem os menores teores de água durante todo o período de acondicionamento.

Temperaturas mais baixas, durante o período de armazenamento, permitem a desaceleração da taxa respiratória da semente, o que pode resultar em menor deterioração da mesma, se o processo for conduzido de maneira adequada para cada espécie armazenada. No entanto, verificou-se que, para a germinação de

Tabela 2. Teor de água de sementes de Physalis angulata L., em função do tempo, recipiente e ambiente de armazenamento (Curitiba, PR, 2012).

\begin{tabular}{|c|c|c|c|c|c|c|}
\hline \multirow{4}{*}{ Embalagem } & \multicolumn{6}{|c|}{ Teor de água das sementes } \\
\hline & \multicolumn{3}{|c|}{ Ambiente controlado } & \multicolumn{3}{|c|}{ Ambiente refrigerado } \\
\hline & 45 dias & 90 dias & 135 dias & 45 dias & 90 dias & 135 dias \\
\hline & \multicolumn{6}{|c|}{$\%$} \\
\hline Vidro & 6,9 & 7,8 & 7,5 & 6,3 & 7,7 & 6,4 \\
\hline Papel & 7,7 & 9,1 & 10,2 & 6,8 & 8,9 & 7,7 \\
\hline
\end{tabular}

Tabela 3. Germinação de sementes de Physalis angulata L., em função do tempo, recipiente e ambiente de armazenamento da semente (Curitiba, PR, 2012).

\begin{tabular}{|c|c|c|c|c|}
\hline \multirow{2}{*}{ Tratamento } & \multicolumn{4}{|c|}{ Avaliação da germinação } \\
\hline & Após colheita (a.c.) & 45 dias a.c. & 90 dias a.c. & 135 dias a.c. \\
\hline Ambiente & \multicolumn{4}{|c|}{ \% Germinação } \\
\hline Controlado & $89 \mathrm{aA}$ & $54 \mathrm{aB}$ & $34 \mathrm{aC}$ & $24 \mathrm{aD}$ \\
\hline Refrigerado & $89 \mathrm{aA}$ & $40 \mathrm{bB}$ & $41 \mathrm{aB}$ & $23 \mathrm{aC}$ \\
\hline $\mathrm{CV}(\%)$ & \multicolumn{4}{|c|}{12,4} \\
\hline Embalagem & \multicolumn{4}{|c|}{ - \% Germinação } \\
\hline Vidro & $89 \mathrm{aA}$ & $43 \mathrm{aB}$ & $36 \mathrm{aC}$ & $24 \mathrm{aD}$ \\
\hline Papel & $89 \mathrm{aA}$ & $51 \mathrm{aB}$ & $39 \mathrm{aC}$ & $23 \mathrm{aD}$ \\
\hline $\mathrm{CV}(\%)$ & \multicolumn{4}{|c|}{12,4} \\
\hline
\end{tabular}


sementes de $P$. angulata colhidas de frutos com cálice verde (Tabela 3), as sementes devem ser usadas logo após colhidas, pois há perda expressiva da viabilidade ao longo do armazenamento, independentemente do ambiente em que esteja armazenada.

Souza et al. (2014) relataram que a diminuição da viabilidade de sementes ortodoxas, durante o período de armazenamento, é representada por uma curva sigmoide negativa, sendo possível observar outro comportamento das sementes, quando são expostas a combinações inadequadas de temperatura e umidade relativa. Vale ressaltar que os efeitos de temperatura e umidade relativa de armazenamento nas variações nas respostas de sementes podem ser atribuídos a diferenças na sua composição estrutural e bioquímica (Rao et al. 2006), associadas ao teor de água inicial das sementes, no período de armazenamento.

Ao analisar a influência da embalagem sobre a germinação das sementes de P. angulata (Tabela 3), verificou-se que não houve diferenças entre o uso de embalagem de vidro ou de papel, para a conservação da qualidade fisiológica das sementes. Sabe-se que o tipo de embalagem utilizada no acondicionamento das sementes, durante o armazenamento, está diretamente associado à manutenção da viabilidade das sementes (Kuhn et al. 2012).

Embora diferenças não tenham sido observadas no uso das embalagens hermética (vidro) ou porosa (papel), no acondicionamento de sementes de $P$. angulata (Tabela 3), esse fator tem influenciado outras solanáceas. Em trabalho conduzido por Oliveira et al. (2003), foi verificado que sementes de pimentão revestidas (apresentam camada fina de um polímero à superfície da semente) deterioraram-se mais rapidamente do que as não revestidas, quando armazenadas em embalagem permeável. Entretanto, Kuhn et al. (2012) indicaram, para sementes de tomate, embalagens herméticas, por serem adequadas à manutenção da viabilidade das sementes.

Constatou-se que as sementes de $P$. angulata perderam quase $50 \%$ da sua viabilidade após 45 dias de armazenamento (Tabela 3). Por serem ortodoxas, as sementes de $P$. angulata toleram a perda de água até níveis seguros para o seu armazenamento. Assim, entende-se que a conservação dessas sementes por período superior a 45 dias poderia ser diferente, se o seu teor de água fosse ainda mais reduzido.

Carvalho \& Nakagawa (2000) recomendam que sementes embaladas em recipientes herméticos devem apresentar variação no teor de água entre 4,0\% e $8,0 \%$. O armazenamento de sementes ortodoxas com reduzido teor de água possibilita a manutenção da viabilidade dos materiais biológicos por mais tempo, uma vez que a taxa respiratória será reduzida (Nascimento 2009).

Pelos resultados obtidos na pesquisa, observou-se que sementes advindas de frutos com cálice amarelo ou amarelo-amarronzado foram aquelas com a menor viabilidade, em comparação às advindas de frutos de coloração do cálice verde. Portanto, o momento indicado pela literatura para a colheita de frutos não coincidiu com o ponto de maturidade fisiológica das sementes, uma vez que, à medida em que os frutos se aproximavam do ponto de colheita "comercial" (realizado pelos produtores, quando o fruto apresenta alto teor de açúcar), as sementes apresentavam uma queda na germinação.

Constatou-se, também, que o armazenamento das sementes, tanto em embalagem porosa quanto hermética, não foi adequado para a manutenção da viabilidade das sementes, em ambos os ambientes de armazenamento testados. Dessa forma, mais estudos que possibilitem analisar distintas formas de armazenamento são relevantes, visando a prolongar o período compreendido entre a colheita e a semeadura seguinte.

\section{CONCLUSÕES}

1. As sementes de Physalis angulata L. devem ser obtidas de frutos com cálice de coloração verde e utilizadas logo após a colheita.

2. O armazenamento de sementes de Physalis angulata L. não é recomendado em condições de ambiente com $14^{\circ} \mathrm{C}$ e $60 \%$ UR (câmara de armazenamento) e $7 \pm 2^{\circ} \mathrm{C}$ e $45 \%$ UR (refrigerado).

3. Não houve influência das embalagens de vidro ou de papel na viabilidade das sementes de $P$. angulata L., durante 135 dias de armazenamento.

\section{REFERÊNCIAS}

ANDRADE, L. Physalis ou uchuva: fruta da Colômbia chega ao Brasil. Revista Rural, São Paulo, n. 38, p. 1112,2008 .

ÁVILA, A. J. et al. Influencia de la madurez del fruto y del secado del cáliz en uchuva (Physalis peruviana L.), 
almacenada a $18^{\circ} \mathrm{C}$. Acta Agronómica Colombiana, Bogotá, v. 55, n. 4, p. 29-38, 2006.

BRASIL. Congresso Nacional. Instrução Normativa ${ }^{\circ} 45$, de 17 de setembro de 2013. Dispõe sobre os padrões para a produção e a comercialização de sementes. Diário Oficial da União, Brasília, DF, 18 set. 2013. Seção 1, p. 16.

BRASIL. Ministério da Agricultura, Pecuária e Abastecimento. Secretaria de Defesa Agropecuária. Regras para análise de sementes. Brasília, DF: MAPA/ ACS, 2009.

CARVALHO, N. M.; NAKAGAWA, J. Sementes: ciência, tecnologia e produção. 4. ed. Jaboticabal: Funep, 2000.

CHITARRA, M. I. F.; CHITARRA, A. B. Pós-colheita de frutos e hortaliças: fisiologia e manuseio. 2. ed. Lavras: UFLa, 2005.

D'ARCY, W. et al. Solanaceae. Flora of the Venezuela's Guyana, London, v. 9, n. 1, p. 194-246, 2005.

DIAS, D. C. F. Maturação de sementes. Seed News, Pelotas, v. 5, n. 6, p. 22-24, 2001.

FISCHER, G.; MARTÍNEZ, O. Calidad y madurez de la uchuva (Physalis peruviana L.) en relación com la coloración del fruto. Agronomía Colombiana, Bogotá, v. 16, n. 1, p. 35-39, 1999.

HUNZIKER, A. T. The genera of Solanaceae. Ruggel: Lichtenstein, 2001.

KUHN, P. R. et al. Influência do tipo de embalagem na qualidade fisiológica de sementes de tomateiro, durante a comercialização. Enciclopédia Biosfera, Goiânia, v. 8, n. 14, p. 692-698, 2012.

LIMA, C. S. M. et al. Características físico-químicas de physalis em diferentes colorações do cálice e sistemas de condução. Revista Brasileira de Fruticultura, Jaboticabal, v. 31, n. 4, p. 1060-1068, 2009.

LOPES, D. C. D. X. P. et al. Atividade antimicrobiana e fototóxica de extratos de frutos e raízes de Physalis angulata L. Revista Brasileira de Farmacognosia, Curitiba, v. 16, n. 2, p. 206-210, 2006.

LORENZI, H.; MATOS, F. J. A. Plantas medicinais do Brasil: nativas e exóticas. 2. ed. Nova Odessa: Instituto Plantarum, 2008.
NASCIMENTO, W. M. (Org.). Tecnologia de sementes de hortaliças. Brasília, DF: Embrapa Hortaliças, 2009.

OLIVEIRA, J. A. et al. Desempenho de sementes de pimentão revestidas com diferentes materiais. Revista Brasileira de Sementes, Pelotas, v. 25, n. 2, p. 36-47, 2003.

ORO, P. et al. Metodologia para teste de envelhecimento acelerado em sementes de fisális (Physalis peruviana). Cultivando o Saber, Cascavel, v. 5, n. 3, p. 167-175, 2012.

RAO, R. G. S. et al. Storability of onion seeds and effects of packaging and storage conditions on viability and vigour. Scientia Horticulturae, Amsterdam, v. 110, n. 1, p. 1-6, 2006.

RODRIGUES, F. A. et al. Caracterização do ponto de colheita de Physalis peruviana L. na região de Lavras, MG. Bioscience Journal, Uberlândia, v. 28, n. 6, p. 862$867,2012$.

RUFATO, L. et al. Aspectos técnicos da cultura da physalis. Lages: CAV/UDESC, 2008.

SILVA, F. A. S. Sistema de assistência estatística - Assistat. Versão 7.6 beta. Campina Grande: UFCG, 2008.

SOARES, M. B. P. et al. Physalins B, F and G, secosteroids purified from Physalis angulata L., inhybity lymphocyte function and allogeneic transplant rejection. International Immunopharmacology, Amsterdam, v. 6, n. 3, p. 408-414, 2006.

SOUZA, C. L. M. et al. Morfologia de sementes e desenvolvimento pós-seminal de Physalis angulata L. Acta Botanica Brasilica, Belo Horizonte, v. 24, n. 4, p. 1082-1085, 2010.

SOUZA, M. O. et al. Germinação de sementes osmocondicionadas e não osmocondicionadas e crescimento inicial de Physalis angulata L. (Solanaceae) em ambientes salinos. Acta Botanica Brasilica, Belo Horizonte, v. 25, n. 1, p. 105-112, 2011.

SOUZA, M. O. et al. Preconditioning of Physalis angulata L. to maintain the viability of seeds. Acta Amazonica, Manaus, v. 44, n. 1, p. 153-156, 2014.

SOUZA, V. C.; LORENZI, H. Botânica sistemática: guia ilustrado para identificação das famílias de angiospermas da flora brasileira, baseado em APG II. São Paulo: Instituto Plantarum, 2005. 